\title{
Continent Urinary Diversions in Non Oncologic Situations: Alternatives and Complications
}

\author{
Ricardo Miyaoka and Tiago Aguiar \\ Division of Urology, State University of Campinas, Sao Paulo, \\ Brazil
}

\section{Introduction}

Urinary diversion is a detour of the urinary tract. It may be necessary in different scenarios and can either be continent or incontinent, catheterisable or orthotopic. Pathological situations which may demand a urinary diversion are varied and include anatomical, physiological, congenital and traumatic causes, e.g. urethral stenosis and partial or complete urethral disruption; bladder dysfunction secondary to radiotherapy or congenital pathologies (posterior urethral valve, Prune-Belly Syndrome, epispadias, bladder extrophy, cloaca); neurogenic bladder and idiopathic bladder dysfunction [1-3].

The treatment has essentially four main goals: preservation of the upper urinary tract, urinary continence, adequate reservoir emptying and avoidance of urinary tract infections [4]. With the continued development of less invasive treatments for almost all urological pathologies (including severe bladder dysfunction) surgical urinary diversion can be currently considered the end treatment for these patients $[2,4,5]$.

Urinary diversion can be classified as either continent or incontinent. Continent urinary diversion refers to a reservoir which can be emptied through clean intermittent catheterization (CIC). Incontinent diversion refers to situations where a continuous free urinary flow through an interposed intestinal segment pours into a collecting bag [2].

Although being a realistic alternative to treat patients with a compromised bladder or urethra, one must be aware of the inherent challenges and possible complications related to urinary diversion. This encompasses not only the surgical aspects, but also the post operative care and management of complications.

We review pre and post operative aspects related to the continent urinary diversion commonly used in benign pathologies and the current literature pertaining to this.

\section{Selection criteria for urinary diversion}

The ultimate aim in reconstruction of the lower urinary tract in patients with adequate storage function is to attain continence. Adequate emptying can be achieved with consideration of manual dexterity, cognitive capability and patient choice. The options to create a continent or incontinent urinary system can range from long-term catheterisation, intermittent cathterisation or diversion - incontinent, or continence cutaneous. 
Ultimately there is no hard and fast answer for every situation, rather an individualised decision must be made.

\subsection{Pre operative evaluation}

Physical examination should determine patient's cognitive capacity to perform self catheterisation. The body habitus may strongly influence the sitting position of the urinary stoma. Attention must be given on how the urine collecting bag plate will adhere to the patient's skin, whether it is going to adequately cope with the external abdominal wall when patient is sitting or standing, etc. It is a useful tip to delineate and mark the exact site where the stoma should be before patient is taken to the operating room.

Comorbidities that may impair patient's ability to properly heal such as uncontrolled diabetes or immunodeficient states must be set even beforehand.

The description by McGuire and cols. [6] that storage leak point pressures above $40 \mathrm{cmH}_{2} \mathrm{O}$ would jeopardize the integrity of the upper urinary tract set a reference value for urodynamic monitoring and treatment orientation. Urodynamics is also helpful in identifying or confirming detrusor overactivity and determining maximum capacity and compliance.

Upper urinary tract preservation is the corner stone of dysfunctional voiding patient management. Upper tract evaluation can be simply performed through an abdominal ultrassonography which is a non invasive procedure that provides valuable information on kidneys morphological features such as shape and size, which may preclude congenital pathologies, anatomical variances, parenchymal scars, and others [1]; and serum labs (urea, creatinine). Creatinine clearance is also recommended to assess global renal function. Evidence of renal atrophy or changes in shape that might suggest impairment of renal function, including previous history of recurrent urinary tract infection (UTI) must be confirmed with static renal scintigraphy (DMSA). This will provide precise information on the patient's baseline renal function status at the beginning of treatment and allow for future monitoring and assurance of renal preservation through comparative analysis. Renal function deterioration is an important landmark to decide upon indicating a reconstructive procedure in this specific population. As such, it seems obvious that prevention of UTIs is critical. An adequate global renal function will reduce the chance for acid/base imbalances secondary to intestinal absorption. However, regular monitoring is needed.

Whenever ureteral dilation is identified, assessment with DTPA or MAG-3 scintigraphy is recommended to rule out ureteral obstruction which may occur as a consequence of bladder wall thickening as well as urethrocistography which will identify possible associated secondary vesicoureteral reflux. In these cases ureteral reimplantation may be needed. This evaluation will not only assure ureteral patency but also determine renal split function.

Urodynamic evaluation is mandatory when bladder dysfunction is suspected. When considering a catheterizable channel, one must be certain about the bladder normal capacity and compliance. Otherwise an augmentation procedure may be necessary in association. Also, continence evaluation may indicate the need for an anti incontinence procedure such as bladder neck closure. This is recommended when urinary leak pressures are detected below $30 \mathrm{~cm} \mathrm{H}_{2} \mathrm{O}$. Videourodynamics combine conventional urodynamics with contrast imaging providing both functional and morphological information at once $[4,15]$. 
Patient must present manual dexterity to firmly hold a catheter and accurately introduce it into the channel lumen. Previous abdominal surgeries and obesity may anticipate surgical difficulty to prepare and externalize the intestinal channel.

Continence must be pursued when feasible. In this sense, self catheterisation need to be adjusted in order to empty the bladder before it reaches its maximum capacity in an attempt to significantly reduce incontinence episodes in between intervals. Bladder capacity may be optimized with the rationale use of anticholinergic agents which may control unhibited detrusor contractions, maintain storage volumes and prevent the development of poor compliance $[7,8]$.

An improvement in Quality of Life (QoL) is a consequence of the above mentioned measures. Increase in patients' self-esteem and the perception of self control and physical independence all contribute as well.

In a recent work, Lee et al. [9] reviewed QoL assessed using validated tools comparing continent $x$ incontinent urinary diversions in cystectomized patients. Orthotopic diversions did not provide overwhelming or major QoL benefit over an incontinent cutaneous diversion at one year follow up after surgical treatment. Although cancer treated patients are not the exact same as neurogenic bladder ones, results could be extrapolated in regards to urinary habit satisfaction and adaptation.

\subsection{Patient education and training}

It is of utmost importance for patients to be adequately informed on the details involving intermittent self catheterization in order to avoid complications.

A review by Moore et al. [10] showed no convincing data favoring any specific catheterization technique (clean vs sterile), catheter type (coated vs uncoated), method (single vs multiple use) or person (self vs other). Different catheter types, materials and sizes can be tested depending on patient preference. Accessories may ease the procedure execution including catheter mirror, knee spreader with mirror, catheter holder. Regardless of using these, catheterization education and support is fundamental [11]. The nurse or physician should assess patient knowledge about the urinary tract; an overview of the perineum and urinary tract through pictures, figures and videos may be very helpful. Nurse should also assess the patient's ability to learn intermittent self-catheterization, awareness of problems related to it, motivation to continue long-term catheterization and the understanding of how to avoid possible complications [11].

\section{Selecting the urinary diversion}

As mentioned previously, urinary diversion (continent versus incontinent) must be based upon: patient's wishes; patient's manual dexterity to perform self catheterization; availability of a care provider; surgical feasibility; quality of life and life expectancy.

Whenever possible, patient's wishes regarding an incontinent conduit or an abdominal catheterizable stoma should be considered. This may result in better acceptance of the urinary diversion and therefore improve quality of life.

While a catheterizable conduit will demand a caregiver's attention every 4 to 6 hours to keep it down to the maximum storage capacity, an incontinent one may yield several hours 
until the urine collecting bag is full. Changing a collecting bag is incomparably easier than catheterizing a Mitroffanof channel and may significantly facilitate the caregiver's task.

Surgical feasibility of the desired urinary derivation must be assessed taking into account:

a. Previous surgical interventions:

A patient who has undergone a previous laparotomy is at risk of adhesions which can confer risk of intertinal injury and difficulty intraoperatively. If a Mitroffanof procedure is planned the presence or absence of cecal appendix will dictate whether a small bowel segment will be needed instead. In patients with previous enteric resection the residual bowel segments care must be taken not to leave the patient at high risk of a malbsorption syndrome.

With abdominal scars the resultant stoma must be fashioned without risk of ischaemia to the skin flap. Any associated abdominal wall defects will also require attention with wound closure or even access into the abdomen.

b. Obesity:

Ileal conduit externalization may be challenging in obese patients. It is important to properly anticipate the adequate intestinal loop length to assure its passage through the abdominal wall and subcutaneous tissue and also to invert the mucosal end providing an elevated "volcano-like" border. This will allow urine to flow right into the collecting bag, sparing the skin and decreasing the incidence of ammoniac dermatitis.

When externalizing a catheterizable channel, using the umbilicus may overcome the large abdominal wall width challenge.

Finally, quality of life anticipation will be most closely met when detailed preoperative planning is made in order to understand patients' expectations and the attending team is able to anticipate and clarify the patient how his routine will be with the chosen urinary diversion (frequency needed to catheterize or exchange the collecting device; changes in his physical appearance; possible related complications, etc).

The available surgical technique can be divided into continent catheterizable channels (Mitrofanoff procedure and Yang-Monti technique) and incontinent conduits (Bricker procedure and ileovesicostomy). Cutaneous ureterostomy is no longer used in current practice due to its high incidence of related complications and stomal stenosis [4].

\subsection{Catheterizable channels: Mitrofanoff and Monti procedures}

The principle of continent urinary diversion (Mitrofanoff principle) is similar to the one which prevents vesicoureteral reflux: to create a submucosal conduit that colapses whenever the reservoir is full preventing urinary leakage through the diversion. This is attained via a Mitrofanoff channel which is a small calibre tube that provides external access to the bladder. Clean intermittent catheterization allows for proper reservoir emptying [12,13].

This type of diversion can benefit patients with refractory urinary incontinence along with a procedure to increase the bladder outlet resistance without incontinence (bladder neck 
closure or tight pubovaginal sling); it may facilitate CIC execution in patients with difficulty to access their own urethra (spastic lower limbs, lack of manual dexterity) or who refuse to catheterize due to pain; and it may also offer an option for bladder emptying in patients with complex urethral stenosis [12,14].

\subsection{Mitrofanoff}

In 1980, Paul Mitrofanoff made the first description on the use of a continent urinary catheterizable channel utilizing the appendix which was later popularized by Duckett et al. [3,12]. The Mitrofanoff principle consists in a urinary continent derivation brought to the skin anastomosed to a low pressure reservoir utilizing an anti reflux technique through which one can perform the CIC [13]. Ideally, the stoma should be easily accessible and aesthetically pleasant [13].

The rationale behind the Mitrofanoff procedure is the maintenance of a low pressure reservoir in which filling pressures do not exceed $20 \mathrm{cmH}_{2} \mathrm{O}$, while conduit pressure stands within $45-90 \mathrm{cmH}_{2} \mathrm{O}$ and reaches up to $80-150 \mathrm{cmH}_{2} \mathrm{O}$ under Valsalva maneuver [16].

\subsection{The appendix}

The use of the appendix by Mitrofanoff to constitute a catheterizable channel was due to several advantages: it is not a vital organ; its function is uncertain after childhood and puberty, when it has an assumed imunological role; it is easy to mobilize and has a convenient location and an adequate length; has a predictable and reliable irrigation and a steady inner lumen which permits the passage of a 10F catheter $[17,18]$. Mitrofanoff also described the use of the ureter as a conduit. This, however, is associated with some morbidity which are hard to overcome and limit its use: need for a transureteroureterostomy; limited mobilization; inconsistent irrigation; painful catheterization and high complication rates including stenosis and incontinence. Other options have been described such as tubularized stomach flap, cecum, colon, Meckel diverticulum, bladder, skin, prepuce, clitoris, uterine tube and vas deferens. These, however, have not reached the same acceptance as the appendix $[15,17,19]$.

\subsection{Surgical technique}

Surgical approach can be accomplished through an infraumbilical median laparotomy or through a Pfannenstiel incision. The appendix is carefully dissected off of the cecum along with its mesentry. The organ is catheterized with a 12 or $14 \mathrm{~F}$ catheter to assure adequate patency. Next, the catheterizable channel implant is performed either onto the bladder or the ileal segment when dealing with an augmented bladder. Absorbable sutures are used and care is taken to execute a 3-4 cm long anti-reflux tunnel (maintaining a length: diameter ratio of 5:1). Patency must be retested at the end of the implant $[3,12,15,20]$.

Stomal externalization through the abdominal wall also requires attention to detail: it should be easily accessible to the patient's dominant hand and allow effortless access to the reservoir. Aesthetic appearance should also be pursued as long as it does not compromise functionality. Stoma externalization is usually made at the umbilicus or at the right lower quadrant. A stoma therapist is key for adequate positioning. There are several techniques 
described for the anastomosis between the conduit and the skin aiming to avoid stomal stenosis. They include V-flaps, tubular skin flaps and V-quadrilateral-Z flaps. Ideally, the conduit should be as short and straight as possible in order to avoid kinking. On the other hand, there must be no tension to the anastomosis [21-24]. Optimal drainage should be maintained post operatively. This is best accomplished with a combination of suprpubic catheterisation and a cathter through the channel.

Conduit Foley catheter is removed 3 to 6 weeks after surgery. Suprapubic cystostomy is clamped and CIC is initialized. Cystostomy may be unclamped at the end of catheterization. Once the patient is familiar with CIC technique cystostomy is definitively removed $[3,12,15]$.

\subsection{Yang-Monti}

In 1993, Yang described the transversal tubularization of two previously detubularized intestinal ileal segments [25]. This technique, however, was only popularized in 1997 by Monti et al. who described its use in dogs [26].

The Monti conduit became a very important option especially in patients who are candidates for a catheterizable channel but have already undergone apendicectomy $[12,15,19,26]$.

\subsection{Surgical technique}

The most important aspect for the length of the channel is the width of the abdominal wall, which should be measured in advance with the aid of a long needle [25]. The conduit short arm must be equivalent to this length. It is important to keep in mind that the diameter of the intestinal loop and not its length is the factor that is going to determine the conduit final length [27]. To obtain a longer conduit, two ileal detubularized tubes in sequence may be anastomosed [26].

In order to avoid complications secondary to malabsorption of vitamin B12 the final $15 \mathrm{~cm}$ of the ileum are spared [27]. A $2-2.5 \mathrm{~cm}$ long intestinal segment is isolated along with its vascular pedicle. This length will allow the passage of a $16 \mathrm{~F}$ catheter. Intestine is opened longitudinally and the distance from the incision to the mesentry should be equal to the one anticipated for the conduit short arm. The segment is then tubularized transversally over a 12-14F catheter using absorbable suture $[26,27,28]$.

Double conduits can be made of $4-5 \mathrm{~cm}$ of intestinal segment. Four sutures ( 2 at each end of the segment, one at the mesentry and the other at the anti mesenteric border) allow adequate traction and division of the intestinal loop. The two segments are incised $5 \mathrm{~mm}$ from the mesentry border and sutured together by the short arm with separate sutures to avoid stenosis. Tubularization is carried out in the same fashion as for single conduits. The centrifuge circulation guarantees proper perfusion and allow tailoring of the distal ends of the conduit in case it is too long [27].

The reservoir should be anchored to the deep surface of the abdominal wall immediately adjacent to the point where the channel was implanted in order to provide stability, avoid reservoir migration and conduit kinking. As mentioned for the Mitrofanoff procedure, a Foley catheter should be placed at the end of the procedure through the conduit associated with a suprapubic cystostomy [26]. 
On the first post operative day, irrigation of the reservoir using the suprapubic catheter is started to reduce mucus plug formation. Within 3 to 6 weeks the conduit Foley catheter is removed, cystostomy is clamped and CIC is commenced. Once the patient is familiarized with the procedure and is fully adapted suprapubic cystostomy is removed definitively $[25-27,29]$.
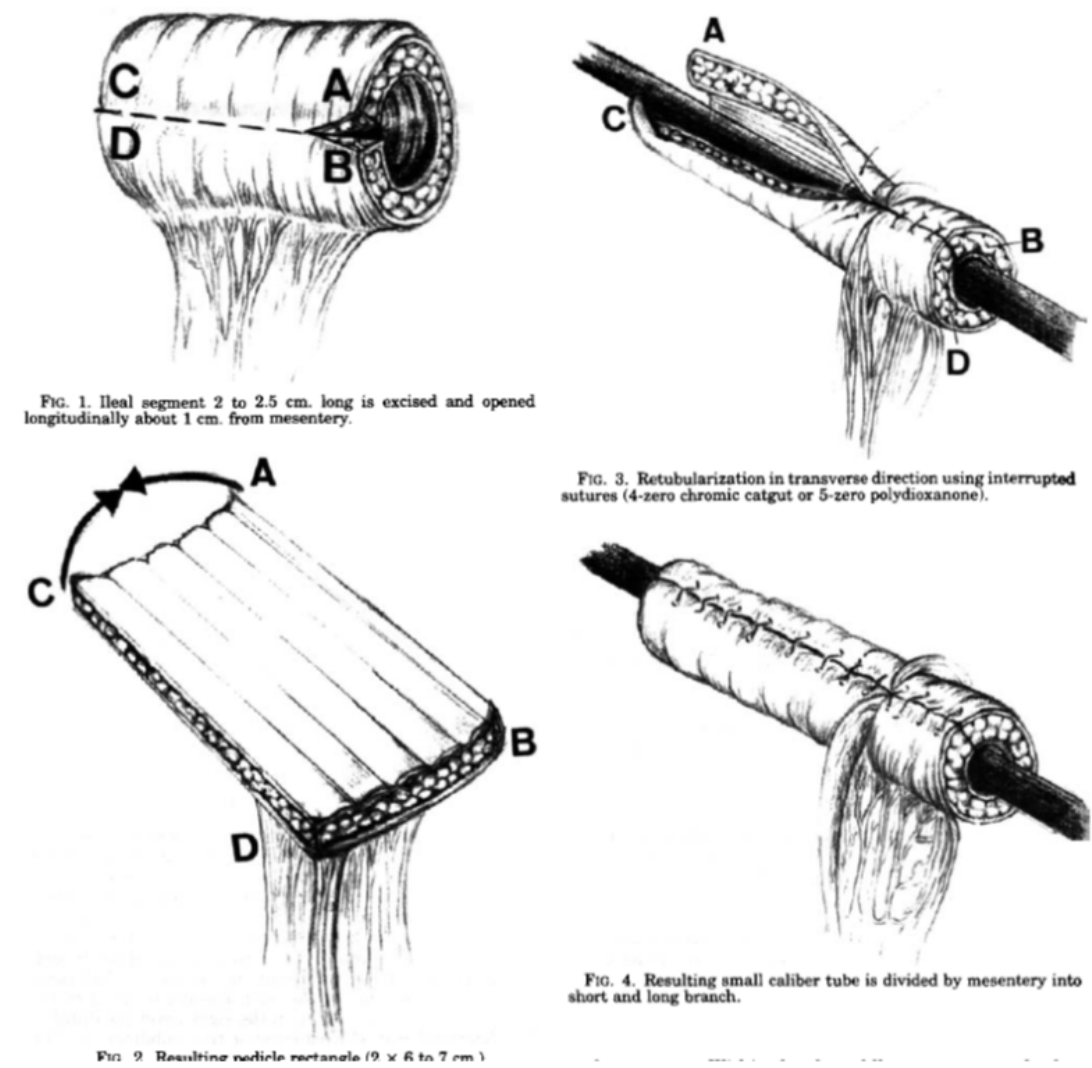

Fic. 3. Retubularization in transverse direction using interrupted sutures (4-zero chromic catgut or 5-zero polydioxanone).

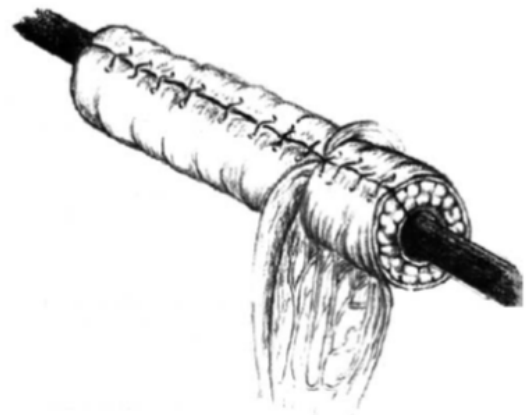
F10. 4. Resulting amall caliber tube is divided by mesentery into
short and long branch.

From: Gerharz EW, Tassadaq T, Pickard RS, Shah PJ, Woodhouse CR, Ransley PG. Transverse retubularized ileum: early clinical experience with a new second line Mitrofanoff tube. J Urol 1998; 159: 525-528.

\subsection{Outcomes}

The risk for some early complications is common to any abdominal surgical intervention involving the urinary and gastrointestinal tracts: bleeding, infection, ileus, intestinal and urinary fistulas, intestinal obstruction, conduit ischemia, abscess, pyelonephritis and sepsis are included [1,14].

Long term follow up series show results for both Mitrofanoff and Monti interventions exceeding $90 \%$ continence rates. Sahadevan et al. reported a self-reported continence rate of $89 \%$ with a mean follow up time of 126 months [30]. Incontinence may occur through the urethra or the conduit $[20,21,31,12-14,17,27-29,32-34]$. 
Most reports comparing the two types of channel did not show differences in continence rates when comparing site of conduit implantation into the native bladder versus bowel $[21,35]$.

Whenever there is an indication for occlusion or reinforcement of the bladder neck resistance different procedures may be considered including a "tight" sling, periurethral bulking agents injection, or bladder neck closure. In a retrospective study, De Troyer et al. [36] compared bladder neck closure with reconstructive procedures aiming to reinforce the bladder outlet resistance in a pediatric population showing a higher continence rate in the former, with no increase in morbidity (such as stone formation and stomal stenosis) or relationship with augmentation procedures. The authors highlight the need for concern when considering a bladder neck closure as access to the reservoir and to the upper urinary tract may become more difficult [36].

In Yang's original study, two main areas of elevated pressure were identified: bladder submucosal tunnel and the segment crossing the abdominal wall. Under Valsalva maneuver simultaneous pressure onto the conduit and the reservoir occurs, but not in the area through the abdominal wall [25]. As such, continence is highly dependent on the submucosal tunnel.

\section{Surgical complications and treatment options}

Overall complication rates are reported to be high and depend on the follow up time but may be estimated between 23 to $36 \%$ for appendicostomies $[37,38]$.

The complications related to stoma represent the vast majority of those found in urinary diversion procedures involving a conduit. Many of these are consequences of preventable technical errors during surgery [39]. Retraction, stomal prolapse, parastomal hernia, and stenosis are the most frequent. Stenosis occurs in up to $33 \%$ of patients and is considered one of the major complications [39-43]. Stomal stenosis can result from a combination of factors, including ischemia, fascial contraction, retraction, local skin alterations, and stoma placement [37, 39]. Long term stenosis at the skin level has been shown to be preventable with the aid of a silicon device (ACE stopper, Medicina, Adlington, UK) by Lopez et al. [44]. In a retrospective study comparing VQZ technique, TSF technique and the umbilicus for stoma confection Landau et al. found VQZ plasty the most effective (patency rates 100\%, $55 \%$ and $74 \%, \mathrm{p}<0.001$ ) hypothesizing this might be a consequence of better blood supply which would come from 3 different sources [23].

Welk et al. reported higher complication rates with Monti technique than Mitrofanoff $(60 \%$ versus 19\%, respectively) [18] although McAndrew et al. found more problems with appendicovesicostomy [21]. In a very recent report, Leslie et al. found no difference in complication rate comparing the two channel types [45]. CIC execution seems also to be more difficult after a Yang-Monti ileovesicostomy technique compared to the appendix. Narayanaswamy et al. reviewed patients who underwent apendicovesicostomy with those who had a Monti conduit. He found a $27 \%$ vs. $60 \%$ rate of problems to catheterize, respectively. Among Monti cases, there was a detectable stenosis in half (13 out of 25 patients). The authors observed the formation of "pouch-like dilatations" along the ileal channel and hypothesized this to be secondary to the creation of a zone of weakness resulting from the rearrangement of muscle fibers following retubularization which would facilitate "stretching-out" and false passage during catheterization [46]. Other authors 
reported rates of $11 \%$ [47] and $23 \%$ of problems related to catheterization of retubularized intestinal tubes [27]. Management may involve a simple Foley catheter placement for a few weeks or a surgical resection of the pouches [3].

Narayanaswamy et al. also found an incidence of conduit stenosis at the bladder implant of $6 \%$ for appendix and $8 \%$ for Monti tubes. Stomal stenosis occurred in 15\% vs. 16\% comparing appendix and Monti, respectively [46]. Landau et al. reported on a retrospective series comparing different techniques for stoma confection: umibilical flap, tubularized skin flap and TVZ flap. Stenosis rates were $25 \%, 45 \%$ and zero, respectively [23].

Problems suspected to be related to conduit patency should be evaluated using an endoscopic approach or performing a conduitogram. This will allow differentiation between stenosis, pouching or kinking. Definitive treatment may vary from calibration to conduit or stoma surgical revision [3,18,48]. D' Ancona and Miyaoka presented an innovative option for salvage treatment of stomal stenosis that fails more conservative approaches such as dilatations and corticosteroid injections and traditional surgical revisions. In patients in whose stoma was placed in the lower abdomen and had the umbilicus preserved they used an umbilical grafting to reestablish conduit superficial patency. Although follow up was short (up to 6 months) results were promising [48].

In cases where urine leakage happens the valvular mechanism may be defective, the reservoir pressure may be excessively high, or both. Urodynamic study is key to establish the diagnosis [36]. If a high pressure-reservoir is diagnosed bladder augmentation may be considered. On the other hand, if the valve mechanism is the issue a submucosal injection of a bulking agent or surgical revision making the tunnel longer may solve the problem [26]. Bulking agents have conflicting results with reported success rates up to $71 \%$ [49].

Most conduit complications will occur within 2 years from surgery, but even initially stable channels are susceptible to complications and must be reassessed throughout patients' lifetime [18].

Calculi formation and urinary tract infection have a fairly high incidence in continent reservoir patients and may vary from $26-32 \%$ and $19-63 \%$, respectively $[47,50]$. They may be facilitated by mucus formation in patients who undergo bladder augmentation and by the position in which the tube is implanted into the bladder (anteriorly placed tubes drain with lower efficacy than those positioned posteriorly) [51]. Patient compliance with CIC execution may also influence these complication rates [18].

Table 1 compiles comparatively the complication rates between Mitrofanoff and Monti channels (Table 1).

\begin{tabular}{|l|l|l|l|}
\hline & Mitrofanoff & Monti & Author \\
\hline Overall & $19 \%$ & $60 \%$ & Welk et al. 2008 \\
\hline Difficulty to catheterise & $27 \%$ & $60 \%$ & Narayanaswamy et al. 2001 \\
\hline $\begin{array}{l}\text { Channel stenosis at bladder } \\
\text { implant }\end{array}$ & $6 \%$ & $8 \%$ & Narayanaswamy et al. 2001 \\
\hline Stomal stenosis & $15 \%$ & $16 \%$ & Narayanaswamy et al. 2001 \\
\hline Calculi formation & $26-32 \%$ & $26-32 \%$ & Clark et al. 2002; Duckett et al. 1993 \\
\hline Urinary Tract Infection & $19-63 \%$ & $19-63 \%$ & Clark et al. 2002; Duckett et al. 1993 \\
\hline
\end{tabular}

Table 1. Surgical complications and incidence rates 


\section{Final considerations}

Understanding the complexity involving the patients who need a urinary derivation is the cornerstone of treatment success. This includes knowing when and which urinary derivation is more suitable for each situation and assuring an appropriate preparation pre operatively. Proper patient education will facilitate patient's adherence to self catheterization and elevate chances to meet his expectations towards the treatment. It cannot be forgotten that although continent urinary conduits offer a very high rate of success, revisions are expected and may occur throughout patient's entire lifetime. Therefore, regular and thorough follow up is warranted.

\section{List of abbreviations}

CIC - Clean intermittent catheterization

UTI - Urinary tract infection

QoL - Quality of life

\section{References}

[1] Adams MC, Joseph DB. Urinary Tract Reconstruction in Children. In Campbell-Walsh Urology, 9th Ed. 2007, Chapter 124, p. 3656-3702.

[2] Metcalfe PD, Cain MP. Incontinent and Continent Urinary Diversion. Pediatric Urology 2nd Ed. 2010, Chapter 56, p. 737-747.

[3] Farrugia MK, Malone PS. Educational article: The Mitrofanoff procedure. J Ped Urol 2010; 6: 330-337.

[4] Westney OL. The Neurogenic Bladder and Incontinent Urinary Diversion Urol Clin N Am 2010; 37: 581-592.

[5] Lapides J, Diokno C, Silber SJ, et al. Clean, intermittent self- catheterization in the treatment of urinary tract disease. Trans Amer Assoc Genitourin Surg 1971; 63:9296.

[6] McGuire EJ, Woodside JR, Borden TA, et al. Prognostic value of urodynamic testing in myelodysplastic patients. J Urol 1981; 126:205- 209.

[7] Stöhrer M, Murtz G, Kramer G, et al. Propiverine compared to oxybutynin in neurogenic detrusor: results of a randomized, double-blind, multicenter clinical study. Eur Urol 2007; 51:235-242.

[8] Goessl C, Knispel HH, Fiedler U, et al. Urodynamic effects of oral oxybutynin chloride in children with myelomeningocele and detrusor hyperreflexia. Urology 1998; 51:9498.

[9] Lee CT. Quality of life following incontinent cutaneous and orthotopic urinary diversions. Curr Treat Options Oncol 2009; 10: 275-286.

[10] Moore KN, Fader M, Getliffe K. Long-term bladder management by intermittent catheterisation in adults and children. Cochrane Database System Review 2007, 4, CD006008.

[11] Newman DK, Willson MM. Review of intermittent catheterization and current best practices. Urol Nurs. 2011; 31:12-28.

[12] Mitrofanoff P. Cystostomie continent trans-appendiculaire dans le traitement des vessies neurologiques. Chir Pediatr 1980; 21:297- 305. 
[13] Duckett JW, Snyder HM 3rd.Continent urinary diversion: variations on the Mitrofanoff principle. J Urol 1986; 136: 58-62.

[14] Liard AS, Uier-Lipszyc ES, Mathiot A, Mitrofanoff P. The Mitrofanoff Procedure: 20 Years Later. J Urol 2001; 165: 2394-2398.

[15] Kaefer M, Retik AB. The Mitrofanoff Principle in continent urinary reconstruction. Urol Clin N Am 1997; 24:795-811.

[16] Chabchoub K, Ketata H, Fakhfakh H, Bahloul A, Mhiri MN. Continent urinary diversion (Mitrofanoff principle). Physical mechanisms and urodynamic explanation of continence. Progrès en Urologie 2008; 18: 120-124.

[17] Monti PR, Lara RC, Dutra MA, de Carvalho Jr. New echniques for construction of efferent conduits based on the Mitrofanoff principle. Urology 1997; 49: 112-15.

[18] Welk BK, Afshar K, Rapoport D, MacNeily AE. Complications of the catheterizable channel following continent urinary diversion: Their nature and timing. J Urol 2008; 180: 1856-1860.

[19] McLaughlin KP, Keating MA. The appendix in reconstructive urology. Surg Ann 1995; 27: $215-231$.

[20] Furness PD, Malone PSJ, Barqawi A, Koyle MA. The Mitrofanoff principle: innovative applications incontinent urinary diversion. Contemp Urol 2003; 15(1):30-45.

[21] McAndrew HF, Malone PSJ. Continent catheterizable conduits: which stoma, which conduit and which reservoir? BJU Int 2002, 89:86.

[22] Murthi GV, Kelly JH. V-Vplasty: a new technique for providing a resilient skin- lined opening for the Mitrofanoff stoma. Urology 2006; 68:661-662.

[23] Landau EH, Gofrit ON, Cipele H, Hardak B, Duvdevani M, Pode D et al. Superiority of the VQZ over the tabularized skin flap and the umbilicus for continent abdominal stoma in children. J Urol 2008; 180: 1761-1765.

[24] England RJ, Subramaniam R. Functional and cosmetic outcome of the VQ plasty for Mitrofanoff stomas. JUrol 2007; 178:2607-2610.

[25] Yang WH. Yang needle tunnelling technique in creating antireflux and continent mechanisms. J Urol 1993; 150: 830-834.

[26] Monti PR, Carvalho JR, Arap S. The Monti Procedure: Applications and Complications. Urology 2000; 55: 616-621.

[27] Castellan MA, Gosalbez R, Labbie Jr. A, Monti PR. Clinical Applications of the Monti procedure as a continent catheterizable stoma. Urology 1999; 54: 153-156.

[28] Leslie JA, Dussinger AM , Meldrum KK. Creation of continence mechanisms (Mitrofanoff) without appendix: the Monti and spiral Monti procedures. Urol Oncol 2007; 25: 148-153.

[29] Gerharz EW, Tassadaq T, Pickard RS, Shah PJ, Woodhouse CR, Ransley PG. Transverse retubularized ileum: early clinical experience with a new second line Mitrofanoff tube. J Urol 1998; 159: 525-528.

[30] Sahadevan K, Pickard RS, Neal DE, Hasan TS. Is continent diversion using the Mitrofanoff principle a viable long-term option for adults requiring bladder replacement? BJU Int 2008;102:236-240.

[31] Harris CF, Cooper CS, Hutcheson JC, Snyder HM. Appendicovesicostomy: the Mitrofanoff procedure-a 15-Year perspective. J Urol 2000; 163: 1922-1926.

[32] Keating MA, Rink RC, Adams MC. Appendicovesicostomy: a useful adjunct to continent reconstruction of the bladder. J. Urol 1993; 149: 1091-1094.

[33] Van Savage JG, Khoury AE, McLorie GA, Churchill BM. Outcome analysis of Mitrofanoff principle applications using appendix and ureter to umbilical and lower quadrant stomal sites. J Urol 1996; 158: 1794- 1797. 
[34] Sylora JA, Gonzalez R, Vaughn M, Reinberg Y. Intermittent self- catheterization by quadriplegic patients via a catheterizable Mitrofanoff channel. J Urol 1997; 157: 4850.

[35] Piaggio L, Myers S, Figueroa TE, Barthold JS, Gonzalez R. Influence of type of conduit and site of implantation on the outcome of continent catheterizable channels. J Pediatr Urol 2007; 3:230-234.

[36] De Troyer B, Van Laecke E, Groen LA, Everaert K, Hoebeke P. A comparative study between continent diversion and bladder neck closure versus continent diversion and bladder neck reconstruction in children. J Ped Urol 2011; 7: 209-212.

[37] De Ganck J, Everaert K, Van Laecke E, et al. A high easy-to-treat complication rate is the price for a continent stoma. BJU Int 90: 240- 243, 2002.

[38] Thomas JC, Dietrich MS, Trusler L, De Marco RT, Pope JC, Brock III JW et al. Continent catheterizable channels and the timing of their complications. JUrol 2006;176:181620.

[39] Farnham SB, Cookson MS. Surgical complications of urinary diversion. World J Urol 2004; 22: 157-67.

[40] Khoury AE, Van Savage JGV, McLorie GA et al. Minimizing stomal stenosis in appendicovesicostomy: using the modified umbilical stoma. J Urol 1996; 155: 205051.

[41] Barqawi A, Valdenebro M, Furness PD III et al. Lessons learned from stomal complications in children with cutaneous catheterizable continent stomas. BJU Int 2004; 94: 1344-1347.

[42] Blaivas JG, Weiss JP, Desai P, et al: Long-term follow up of augmentation enterocystoplasty and continent diversion in patients with benign disease. J Urol 2005; 173: 1631-1634.

[43] Cain MP, Casale AJ, King SJ, Rink RC. Appendicovesicostomy and newer alternatives for the Mitrofanoff procedure: results in the last 100 patients at Riley Children's Hospital. J Urol 1999; 162: 1749- 1752.

[44] Lopez PJ, Ashrafian H, Clarke SA, Johnson H, Kiely EM. Early experience with the antegrade colonic enema stopper to reduce stomal stenosis. J Pediatr Surg 2007;42:522-4.

[45] Leslie B, Lorenzo AJ, Moore K, Farhat WA, Bagli DJ, Pippi Salle JL. Long- term follow up and time to event outcome analysis of continent catheterizable channels. J Urol 2011; 185: 2298-2302.

[46] Narayanaswamy B, Wilcox DT, Cuckow PM, Duffy PG, Ransley PG. The Yang- Monti ileovesicostomy: a problematic channel? BJU Int 2001; 87: 861-865.

[47] Clark T, Pope JC, Adams MC, Wells N, Brock JW. Factors that influence outcomes of the Mitrofanoff and Malone antegrade continence enema reconstructive procedures in children. J Urol 2002;168:1537-40.

[48] D'Ancona CAL, Miyaoka R, Ikari LY, Nunes PHF. Umbilical grafting in treatment of recurrent stomal stenosis. Urology 2008; 71: 1124-1127.

[49] Prieto JC, Perez-Brayfield M, Kirsch AJ, Koyle MA. The treatment of catheterizable stomal incontinence with endoscopic implantation of dextranomer/ hyaluronic acid. J Urol 2006; 175: 709-711.

[50] Duckett JW, Lotfi AH. Appendicovesicostomy (and variations) in bladder reconstruction. J Urol 1993; 149: 567-569.

[51] Berkowitz J, North AC, Tripp R, Gearhart JP, Lakshmanan Y. Mitrofanoff continent catheterizable conduits: Top down or bottom up? J Pediatr Urol 2009; 5: 122-125. 


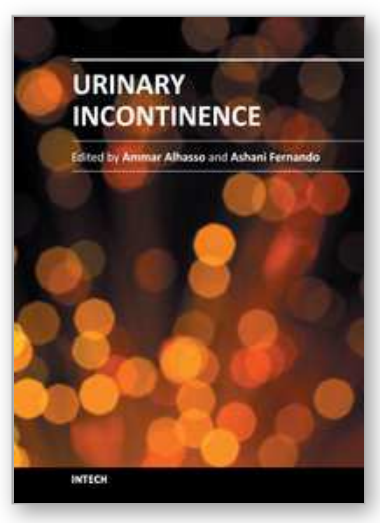

\author{
Urinary Incontinence \\ Edited by Mr. Ammar Alhasso
}

ISBN 978-953-51-0484-1

Hard cover, 324 pages

Publisher InTech

Published online 04, April, 2012

Published in print edition April, 2012

Management strategies are framed within a multidisciplinary team structure and as such a range of specialists ranging from psychologists, specialist nurses, gynaecologists and urologists author the chapters. There are some novel methods outlined by the authors with their clinical application and utility described in detail, along with exhaustive research on epidemiology, which is particularly relevant in planning for the future.

\title{
How to reference
}

In order to correctly reference this scholarly work, feel free to copy and paste the following:

Ricardo Miyaoka and Tiago Aguiar (2012). Continent Urinary Diversions in Non Oncologic Situations: Alternatives and Complications, Urinary Incontinence, Mr. Ammar Alhasso (Ed.), ISBN: 978-953-51-0484-1, InTech, Available from: http://www.intechopen.com/books/urinary-incontinence/urinary-derivationsalternatives-and-complications

\section{INTECH}

open science | open minds

\author{
InTech Europe \\ University Campus STeP Ri \\ Slavka Krautzeka 83/A \\ 51000 Rijeka, Croatia \\ Phone: +385 (51) 770447 \\ Fax: +385 (51) 686166 \\ www.intechopen.com
}

\author{
InTech China \\ Unit 405, Office Block, Hotel Equatorial Shanghai \\ No.65, Yan An Road (West), Shanghai, 200040, China \\ 中国上海市延安西路65号上海国际贵都大饭店办公楼405单元 \\ Phone: +86-21-62489820 \\ Fax: $+86-21-62489821$
}


(C) 2012 The Author(s). Licensee IntechOpen. This is an open access article distributed under the terms of the Creative Commons Attribution 3.0 License, which permits unrestricted use, distribution, and reproduction in any medium, provided the original work is properly cited. 